\title{
Business Model Innovation of Yungang Cultural Industry Based on the "Internet +" Format Perspective
}

\author{
Ruixiong $\mathrm{Qi}^{1 *}$, Ronghua Chang ${ }^{1}$, Danping $\mathrm{Xu}^{2}$, Haiyan $\mathrm{Wu}^{1}$ \\ ${ }^{1}$ Business School, Shanxi Datong University, Datong, Shanxi 037009, China \\ ${ }^{2}$ Foreign Language School, Shanxi Datong University, Datong, Shanxi 037009, China \\ *Corresponding author.Email: qrx_dtdx@163.com
}

\begin{abstract}
Affected by Covid-19, traditional offline cultural industry has been impacted, while online consumption and "Internet + cultural industry" is bucking the trend. "Internet+" is not only a new form of economic development, but also a new format of cultural industry. The development of Yungang cultural industry can use Internet thinking, combine cultural resources, tourism resources, and modern technological resources across fields, and innovate in product content, industrial chain, and business model. Using the AISAS consumer behavior analysis model, the article proposes to apply the Internet technology, e-commerce and online and offline integrated marketing strategy to Yungang cultural industry, realize the industrial integration and innovative development through product innovation and derivative development, make Yungang cultural industry break through the limitations of traditional business model and rejuvenate historical and cultural resources.
\end{abstract}

Keywords: "Internet +", Yungang cultural industry, business model, brand promotion

\section{INTRODUCTION}

The hottest cross-border integration currently is a series of cross-border and integration led by "Internet +", forming a trend that almost no industrial form can be separated from the Internet, and the "Internet $+X "$ pattern is emerging. In recent years, the cultural industry has flourished on Internet platform, such as short video, live broadcast and audio station which have subverted the traditional television and radio industries. Undoubtedly, the integration of cultural industry and "Internet + " indicates future direction of cultural industry development. This article focused on the opportunities and strategies of Yungang cultural industry in the context of epidemic and "Internet + " background, explored a new business model for Yungang cultural industry, with a view to inheriting historical culture and better exerting its commercial value.

\subsection{The Profile of Yungang Cultural Industry}

Yungang cultural industry originates from the cultural tourism industry of Yungang Grottoes, a Chinese historical and cultural heritage. Yungang Grottoes scenic spot is located at the north bank of Shili
River and the south foot of Wuzhou mountain in Datong City, Shanxi Province. It is a giant grotto art featuring Buddhist culture and a treasure of ancient Chinese traditional culture and art. It is the most regional, representative, and symbolic of Buddhist culture. It can be called the pinnacle of Chinese Buddhist art and represents the highest level of world sculpture art in fifth century. Yungang Grottoes has been committed to developing cultural tourism industry, focusing on sustainable industrial development, and turning Yungang Grottoes into a series of famous tourist attractions integrating history, culture and modern civilization.

In recent years, Yungang Grottoes have sought various channels of communication to show its cultural connotation and artistic charm. The construction of Yungang Grand Scenic Area has begun to take shape, forming Lingyan Temple, Tanyao Square, Performing Arts Center, Foguang Avenue, Rock Carvings, Food Street, Longwang Temple Ruins, Yungang Garrison, Yungang Grottoes Exhibition Hall, Ancient Road Rut Sites, Shadow Puppet Performance Hall, and Yungang Painting Academy have gradually formed a characteristic cultural industry cluster [1]. 
Focusing on strategies of scenic spots, tourist routes, supporting facilities, service quality and marketing, Yungang cultural industry has established a global tourism development pattern of multi plate linkage, such as culture, ecology, health care, exhibition, festival, countryside, ice and snow, hot spring, and home stay, to drive the integrated development of relevant industries with cultural industry [2]. Through exploring the "Internet + cultural industry" model, combining with agriculture, industry, health care, sports, ecology, and film, expanded the new forms of cultural industry. Through cooperation with financial media, Datong cultural, tourism, and intangible cultural heritage, food, etc. has increased the popularity of cultural tourism brand of "Ancient Capital of China - Great Harmony in World" and the influence of cultural industry.

\subsection{Analysis of Yungang Cultural Industry Business Mode in the "Internet +" Format}

The offline tourism economy and cultural consumption methods have been forced to block, giving birth to a new format of "Internet + cultural industry", which is a positive impact of the epidemic. Online cultural and entertainment activities emerging, users of social networking, video, online games, e-reading, online education, and other platforms are increasing, the number of active users has also made great breakthroughs. More innovative "cloud culture activities" attracted consumers' attention: "cloud sakura appreciation" launched by Wuhan University in cooperation with many media, "cloud music festival" held by modern sky on Bilibili, and art galleries such as Shanghai boundless and Renaissance Art Center try to launch "Cloud wandering Art Museum"... "Internet + cultural industry" expands the boundaries of traditional cultural industries, relieves people's psychological pressure caused by long-term isolation, and forms a new business model [3].

Focusing on construction of large scenic spots and cultural tourism industry, the traditional Yungang cultural industry is limited by regional of traditional consumption, the cultural products produced and created cannot meet the diverse needs of various consumer groups. The "Internet + " era is an opportunity for the transformation and development of Yungang cultural industry. The cross-border integration of "Internet + cultural industry" involves multiple industrial fields. Yungang cultural industry is no longer confined to cultural tourism and peripheral products. On the Internet platform, break through the space limitations of traditional cultural industries, and enhance the industry's cross-border resource integration capabilities and market competitiveness. At this stage, how to integrate the Internet and cultural industry more effectively is an important strategic layout of Yungang cultural industry.
The application of Internet connects things from all walks of life and blurs the boundary of the industry, so that the cultural industry must closely follow the trend, such as focusing on the development and incubation of IP and exploring the extension of the cultural industry chain. However, the current derivation of cultural products in Yungang cultural industry is not extensive. In addition, the fan economy is also a core element of the cultural industry. Yungang cultural industry lacks consumer cultural identity, and effective fan group support and long-term business development have not been formed. As a new business model, "Internet + cultural industry" has inestimable potential. The epidemic has accelerated the progress of Internet cultural industry and affected the overall consumption structure of cultural industry. The integration of Yungang cultural industry with Internet technology will not only promote the transformation and upgrading of the traditional cultural industry itself, but also facilitate the cross-industry integration of the cultural industry with other industries and form the resources sharing of different industries.

\section{BUSINESS MODEL INNOVATION OF YUNGANG CULTURAL INDUSTRY}

The rapid development of mobile Internet economy has continuously increased the number of Internet users in China. According to China Internet Network Information Center (CNNIC, the 48th "Statistical Report on China's Internet Development Status") data, as of June 2021, China had 21.75 million new netizens, the number of netizens reached 1.011 billion, and the Internet penetration rate reached $71.6 \%$, an increase of $1.2 \%$ compared to 2020 . Among them, the scale of mobile netizens reached 1.007 billion, with 20.92 million new mobile netizens. "Internet + " becomes a high-frequency word, bringing new business opportunities for the development of cultural industry. For example, the traditional paper media -- Forbidden City team, perfectly combines traditional culture with digital application technology, aiming at creating a "digital Forbidden City", launching apps such as "Forbidden City Famous Paintings", "Forbidden City $600 "$ and WeChat mini programs such as "Pocket Palace Craftsman" and "Wondering Forbidden City" to attract users' attention to the culture of Forbidden City. Besides, the elements of the Forbidden City are widely used in cultural and creative products, such as the Forbidden City's "sacred beast" ice cream in the 2020. Therefore, "Internet + " is not only a new form of economic development, but also a new format of cultural industry development. Yungang cultural industry should be deeply integrated with "Internet +", only by innovating product content, industrial chain and business model can expand the development space of characteristic cultural industry. 


\subsection{Innovate the Content of Yungang Cultural Products by Internet Thinking}

Nowadays, the Internet has changed from a tool to a thinking, culture, and even a state of work and life. "Internet + " realizes innovation and fission in the traditional industry through the Internet business mode, which brings economic benefits. Its essential feature is the construction of Internet thinking, which undergoes three levels of transformation: The first level, Internet is a tool, which can improve efficiency and reduce costs; The second level is Internetization, use Internet to change the operation process, create an e-commerce platform and carry out network marketing; The third level is Internet thinking, to realize the integration and development of various industries through "Internet +", transform the business model of traditional industries, and carry out value innovation [4].

Internet thinking is a way of thinking that reexamines the market, users, products, corporate value chain, and even the entire business ecosystem in the context of (mobile) Internet, big data, cloud computing and other technologies. The core view of Internet thinking is user first, experience is king, free mode and subversive innovation. Specifically, it can be divided into three categories: subjective thinking, innovative thinking, and integrated thinking. Subjective thinking includes user thinking, simple thinking, extreme thinking; Innovative thinking includes iterative thinking, flow thinking, big data thinking, and social thinking; Integrated thinking includes platform thinking and cross-border thinking. The fundamental of Internet thinking is "user first". Yungang cultural enterprises involve multiple consumption fields such as catering, culture, tourism, shopping, and entertainment. It is necessary to rethink what kind of cultural consumption is required on the Internet and how to carry out new product iterations on the Internet. This "new" not only requires product innovation in technology and form, but also "new" in concept.

\subsection{Optimize the Structure of Yungang Cultural Industry and Extend the Industry Chain}

At present, Datong City has built Performing Arts Center, Yungang Museum, Liaojin Food and Merchandise Street and Lingyan Temple into a display platform that embodies Yungang culture and Datong history, and deeply explores the historical connotation of Yungang culture. The Food and Merchandise Street introduces cultural companies and well-known local catering companies; Yungang Calligraphy and Painting Academy, Yungang Stone Carving, Daijing Wood Carving, Yungang Silk People, Guangling Papercutting, Lingqiu Silverware and other local cultural specialty stores effectively integrate local characteristics products and folk handicraft resources, creating a good environment and artistic atmosphere for the creation and production of characteristic products. The types of Yungang cultural products have begun to take shape, which greatly enriched the local cultural tourism market and explored a path for the healthy development of cultural industry [5].

In the future, should fully create and release the dividends of "Internet+" era, complete overall layout of Yungang cultural industry, focus on emerging industries such as the Internet cultural industry, and increase research and investment in these, actively build a new pattern of cultural industry based on content and form innovation in the region, so that the Yungang cultural industry can fully integrate with the traditional cultural industry. In the development process of the cultural industry, strengthen the application of big data technology, etc., understand the various cultural needs of users and consumers, on this basis, innovate and upgrade products, precision marketing push, extend the industrial chain, and continue to expand the scale of the industry.

\subsection{Rely on Internet Platform to Innovate the Cultural Industry Business Model}

In the Internet age, the use of digital means to enhance the creativity and influence of historical and cultural heritage has become an important topic. In recent years, intangible cultural heritage live broadcast, "book delivery", cultural and creative product promotion and marketing, and other business models based on "culture + technology" have played an increasingly important role. Live broadcast, short videos, e-commerce, etc. widely used in brand marketing of small and medium-sized enterprises, effectively improving the efficiency of information communication and commodity exchange. The digitization strategy of the cultural industry has accelerated the development of new cultural enterprises, cultural formats, and cultural consumption patterns as the future direction of development. For small and medium-sized cultural enterprises, it is necessary to comply with the trend of digital industrialization and industrial digitization, and promote the application of emerging information technology in the production, dissemination, and consumption of cultural and creative products. Yungang cultural enterprises should pay attention to the scene innovation of digital cultural consumption, and actively use 5G, big data, cloud computing, artificial intelligence and other cutting-edge technologies to expand the types of cultural services and optimize the consumer experience.

At present, various development models such as future model, platform model, advertising and marketing model, and technical service model formed in the process of cultural industry development. Different 
models have unique advantages for the regional characteristics of cultural industry, which promotes the cultural industry business model, formed more paradigms, with more options. Therefore, Yungang cultural industry can choose a development model that suits its actual needs based on a general model. It is necessary to strengthen the application and promotion of new media, realize the innovation of content and form, give full play to the industrial structure advantages of the integration of culture and the Internet, and increase the added value of cultural products.

\section{BRAND CONSTRUCTION AND MARKETING STRATEGY OF YUNGANG CULTURAL INDUSTRY}

The AISAS model was proposed by Dentsu Group in 2005. It is a five-dimensional consumer analysis model of Attention, Interest, Search, Action, and Share and represents the entire process performance of consumers from contact to purchase and after purchase, interprets the behavior of consumers in the Internet era. The biggest difference from traditional marketing methods is that the terminal of the traditional marketing model is consumer's purchase behavior, but consumers in the Internet era can share on the platform after completing the purchase, consumers also participate in product marketing process. Therefore, Yungang cultural enterprises should establish their own brand fans, and realize the marketing strategy of online and offline marketing integration.

\subsection{Create Brand Cultural Derivatives Rely on "Internet + Culture"}

The museum is a place for collecting, storing, displaying, and researching objects representing nature and human cultural heritage. It carries the memory of history and is a symbol of the uniqueness and superiority of a country, nation, city, and culture. The cultural derivatives of the museum contain cultural elements of the museum's collections, and through innovative redesign, products with cultural added value are derived. Many tourists regard the museum as a window to understand local history and culture. The high-quality cultural tourism experience drives the museum's popularity.

Yungang Museum has a profound cultural heritage in its collections, and its market scale and cultural influence are expanding, but the development of museum cultural derivatives is lacking attention. First, the biggest feature of museum cultural derivatives differ from ordinary commodities is to reflect the cultural identity of the museum's collections, but the derivatives currently on the market are in a single form, which is like products sold in other scenic spots, lacks originality, and cannot reflect the museum regional cultural connotation and artistic taste. Second, the styles of Buddhist statues in grottoes have their own characteristics, and the shapes are ever-changing and lifelike. For the design of derivatives, the rich sculpture art of Buddha culture has important reference value in the extraction and application of visual elements, rather than simply copying on the market, lack of creativity in derivatives have reduced tourists' desire [6].

The Yungang Grottoes are rich in cultural resources. Cultural companies should extract Buddhist elements from the grotto modeling, combine with the local characteristics of Datong City, design and recreate a trendy image with strong cultural recognition, new artistic derivatives, and gradually establish own brand image that belong to Yungang [7]. Whether from design or marketing, embarks on a mature industrial chain. Cultural derivatives are the symbols and epitomes of the museum's collection culture. The design of derivatives should reflect differences and have a high degree of cultural recognition. Symbolic symbols should reflect their local regional characteristics and enhance the popularity of the museum through the particularity of cultural symbols. As far as Yungang cultural derivatives are concerned, it can fully tap the characteristics of Buddhist thought and national integration, excavate excellent elements from the history, graphics, patterns, and shapes of the museum collection, apply them to the design, and design derivatives combining the collection culture and consumer demand.

\subsection{Improve Communication Strategies by Self-Media, Converged Media, and E- Commerce Platforms}

Today, the Internet is highly developed, consumer groups are more inclined to obtain information through Internet. Tencent, Baidu, Weibo, Sohu, etc. have started to build self-media platforms, which has enabled selfmedia platforms and have a large number of users. For example, WeChat public account, Weibo, QQ public platform, Tiktok, Baidu Baijia, Toutiao, etc. At present, Yungang cultural industry should build a well-known brand, it can integrate the resources of the self-media platform, select the appropriate platform as the main cultural dissemination position, form a self-media matrix, and effectively disseminate it, to stimulate users' willingness to consume. In addition, companies can also open online stores or marketing communities on Weibo and WeChat platforms to actively communicate and communicate with users and stimulate their consumer interest through interesting and interactive marketing methods.

The key word in the era of converged media is diversification, covering the main body of communication, media, communication context, communication process and effects, etc. The dissemination of Yungang culture can grasp the law of 
communication in the era of converged media and choose appropriate communication channels and methods. Yungang cultural industry should leverage its brand advantages, integrate media resources inside and outside the province, and make every effort to create a new media group with Yungang culture as the theme to promote the excellent Chinese traditional culture, cultivate diversified communication subjects and respect individualized consumer demand and experiences, such as 3D printing, digital murals, VR experience, etc., show the classic artistic charm of Yungang cultural industry in an all-round and multi-level manner, and reflect the perfect combination of modern technology and cultural heritage [8].

\subsection{Realize Precision Marketing and Targeted Promotion Via Search Engines and Big Data Technology}

Search engines can help consumers quickly retrieve target products, but consumers use various data on search engines to become the best channel for companies to understand users. Therefore, Yungang cultural enterprises should use big data thinking, and every information dissemination through official website, WeChat, Weibo, Internet, and mobile terminals can become the sample basis for data collection, analysis, and classification. Classify according to gender, age, preferences, cultural level, acceptance form, degree of participation, etc., [9] draw "personal portraits" of each type of group, infer their general consumption needs, consumption habits and consumption ability, and then match their demands and preferences for products and services. So as to achieve precise communication subsequently, the value of the content is realized to the greatest extent. At the same time, companies can use "Internet + " to continuously introduce new marketing methods and models, such as accurate delivery of marketing information to target customers' mobile app advertising positions and continue to expand the scope of target consumer groups.

\subsection{Establish Cultural Brand Reputation Through Consumer Information Sharing}

In the Internet era, people are surrounded by mass information every day. Yungang cultural enterprises are small in scale and scattered in layout, large and centralized scale effect and agglomeration effect have not been formed. The industrial competitiveness is insufficient and easy to be submerged in the information ocean. Only by complying with the development requirements of the new era, fully utilizing the "Internet plus" thinking, breaking through the two aspects of product innovation and service users, and realizing the integration and innovation development of the industry, these characteristic cultural industries can break through the limitations of the current traditional development model and rejuvenate with vitality.

The quality of personal consumption experience not only determines whether has the willingness to buy again, but also indirectly affects the perception of the brand's products by potential users who browse the web, thereby promoting the formation of the company's reputation in the industry. For example, in recent years, the Palace Museum and Dunhuang Museum have joined hands with the continuous effects of digital technology to bring about high reputation. Therefore, Yungang cultural enterprises can not only improve the consumer experience of users, but also provide a platform for them to share their consumer experience, so as to form a closed loop of the entire consumption process and expand brand influence.

\section{CONCLUSION}

This article analyzes the status quo of Yungang cultural industry under the "Internet + " business model and proposes the path for business model innovation. It is considered that the traditional Yungang culture industry should make full use of Internet thinking to combine cultural resources, tourism resources and modern technology across fields in product content, industrial chain and business model. Moreover, implement the digital strategy of cultural industry and promote the application of digital technology in product production, dissemination, consumption through the Internet platform. Using the "AISAS" model, the article proposes the construction of Yungang cultural industry brand and marketing strategies from four aspects: creating "Internet + culture" derivatives, multi-platform and media technology brand communication, big data and information technology precision marketing, accurate marketing of big data and information technology, and enhancing cultural consumption experience and sharing.

\section{ACKNOWLEDGMENT}

This work was supported by youth project of the 2021 annual planning project of Shanxi Academy of Social Sciences (Development Research Centre of Shanxi Provincial People's Government) (YWQN202110) and the special research project of Shanxi Datong University (2020YGZX098; 2020YGZX070).

\section{REFERENCES}

[1] R.X. Qi, D.P. Xu, H.Y. Wu, Research on the Promotion and Development of Yungang Cultural Industry by Business Model Innovation under the Background of Digital Technology, Open Journal of Social Sciences, vol. 9, 2021, pp. 627-638. DOI: https://doi.org/10.4236/jss.2021.95035 
[2] C.Y. Wang, Deepen the integration and development of cultural tourism and empower the construction of a strong cultural city, Datong Daily, 2021-09-26 (001).

[3] Y.Y. Sun, S.M. Yu, Opportunities and Challenges of the Internet + Cultural Industry-Analysis of New Formats of Cultural Industry Based on the Impact of the New Crown Epidemic, Popular Literature and Art, vol. 14, 2020, pp. 229-230.

[4] Y. Huang, Discussion on the development and innovation of Guangxi's characteristic cultural industry under the background of "Internet+", Journal of Nanning Vocational and Technical College, vol. 29, 2021, pp. 95-99.

[5] B. Jiang, The development status and strategy of China's cultural industry in the Internet + era, Enterprise Reform and Management, vol. 23, 2020, pp. 213-214.

[6] H.Y. Wang, The dissemination strategy of Yungang grotto culture in the context of converged media, Journal of Shanxi Datong University (Social Science Edition), vol. 33, 2019, pp. 52-55.

[7] R.X. Qi, Business Model Innovation of Yungang Cultural Industry under the Direction of Future, International Journal of Intelligent Information and Management Science, vol. 10, 2021, pp. 166-168.

[8] R.Q. Yuan, On the feasibility of the development of museum art derivatives: A case study of Yungang Grottoes Museum, Yalu River, vol. 8, 2015, pp. 170.

[9] Y. Li, The business model of the whole industry chain promotes the development of cultural industry-Discussion on the business model of cultural industry in Hebei Province, Reform and Opening, vol. 22, 2012, pp. 197-198. 